\title{
Una reseña sobre el libro “Del discurso a la gramática en el habla infantil. Cómo los marcadores evolucionan a conectores de construcciones complejas"
}

A review of "From speech to grammar in children's speech. How markers evolve to connectors of complex constructions Children"

Carlos Álvarez E.

Universidad de Chile

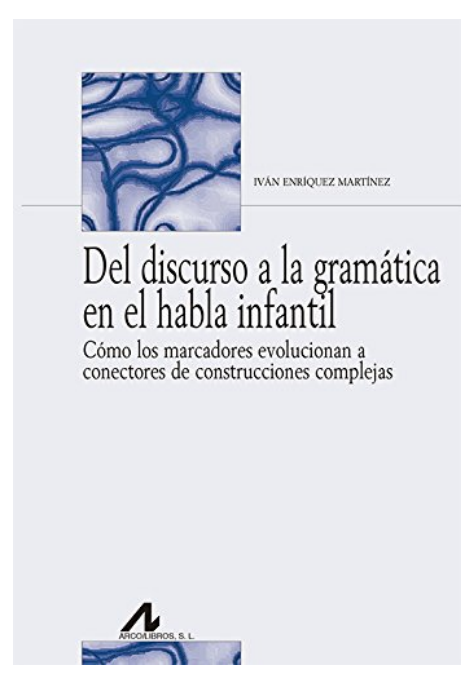

Autor: Iván Enríquez Martínez

Editorial: Arcos Libros

Número de páginas: 240 páginas.

Año: 2017

ISBN: 978-84-7635-958-7 
Desde el año 1984, la editorial Arco/Libros, S.L. ha realizado una significativa contribución en la difusión de trabajos académicos acerca de diversas temáticas, principalmente, relacionadas con la lengua hispánica. En el año 2017, catalogado en su colección Filología (subsección Bibliotheca Philological), esta editorial nos presenta un libro que supone una relevante aportación en el ámbito de la Psicolingüística Evolutiva: Del discurso a la gramática en el habla infantil, de Iván Enríquez Martínez, Doctor en Lingüística Aplicada y Teoría de la Lingüística por la Universidad de Santiago de Compostela, España.

Por décadas, el estudio de las características del lenguaje infantil ha atraído la atención de investigadores de diversas disciplinas académicas. En términos generales, la colaboración interdisciplinaria ha sido fructífera, especialmente, en relación con el proceso de desarrollo comunicativo-lingüístico por parte de niños monolingües hablantes de inglés. En lo que respecta a niños monolingües hispanohablantes, el panorama no parece ser del todo idílico: pese a que el mundo hispano dispone de estudios de excelente calidad académica, asertivamente el autor establece que "el español, a pesar de ser una de las lenguas más habladas del mundo, apenas ha sido estudiado desde el punto de vista evolutivo". Indudablemente, Del discurso a la gramática en el habla infantil viene a contribuir al conocimiento acerca del desarrollo del lenguaje en las primeras etapas del ciclo vital, en general, y de ciertos aspectos de la sintaxis compleja, en particular. Al respecto, Iván Enríquez Martínez centra su atención en el desarrollo de la función sintáctica y pragmática de los conectores: pero, porque, si, pues en habla espontánea por parte de diez niños de entre dos y cuatro años.

Considerable interés despierta la metodología adoptada por el autor para indagar el desarrollo de los conectores antes mencionados. Para ello, Iván Enríquez Martínez analiza, cuantitativa y cualitativamente, muestras de lenguaje oral espontáneo registradas longitudinalmente durante dos años en el contexto que ofrece el jardín infantil de los niños participantes. Las muestras de lenguaje fueron recopiladas del corpus Koiné, cuyos datos se encuentran disponibles en el sistema Child Language Data Exchange System (CHILDES). Infunde indiscutible valor al trabajo no solo la longitudinalidad de las muestras de lenguaje, sino que, en particular, la situación espontánea en que fueron realizados los registros. En 
general, el muestreo y posterior análisis de este tipo de datos constituye un importante desafío para todo investigador. No obstante, los avances observados en materia tecnológica que han sustentado de manera importante el desarrollo de la Lingüística de Corpus han hecho del análisis de muestras de lenguaje oral espontáneo una tarea asequible y totalmente necesaria. En efecto, las herramientas disponibles en el sistema CHILDES, en particular el paquete de programas CLAN, permitió al autor el examen exhaustivo de las más de diez mil muestras de lenguaje producidas por los niños participantes que arrojó seiscientos veintiocho instancias de uso contextualizado de los conectores: pero, porque, si, pues.

Del discurso a la gramática en el habla infantil cuenta con una organización que favorece la lectura y la comprensión de la temática tratada. Este cuenta con dos secciones: la primera, titulada Fundamentos teóricos y metodológicos, entrega al lector una lúcida descripción del andamiaje que sustenta la indagatoria realizada, en tanto que la segunda, Estudio evolutivo de las construcciones complejas, da a conocer los hallazgos y cómo éstos contribuyen a la caracterización de las rutas evolutivas de complejidad sintáctica que emprenden los niños desde temprana edad. Esta segunda sección alberga los resultados obtenidos, a los cuales el autor dedica un capítulo para cada conector pesquisado. Cabe destacar que la exposición de los resultados es clara y profusamente ejemplificada con extractos de las muestras analizadas.

Los interesantes hallazgos del estudio realizado por Iván Enríquez Martínez dan cuenta de un fenómeno especialmente relevante para personas cuyo quehacer científico o profesional se vincula con el desarrollo infantil, en especial los terapeutas del lenguaje. Conocer las características que presenta el desarrollo de la complejidad sintáctica en niños con desarrollo típico permite determinar los parámetros que guían el diagnóstico y planes de tratamiento para niños que presentan trayectorias de desarrollo menos típicas. En definitiva, Del discurso a la gramática en el habla infantil representa una fuente de información ineludible en la aproximación al trabajo relacionado con el desarrollo del lenguaje infantil. Asimismo, la lectura de esta obra invita a continuar explorando las particularidades de un desarrollo cuya dinamicidad y complejidad son solo observables en el desenvolvimiento espontaneo de un niño en contextos variados. Una obra recomendada. 